\title{
CLASSE E LINGUAGEM: NOTAS SOBRE O DEBATE EM TORNO DE LANGUAGES OF CLASS DE STEDMAN JONES
}

\author{
Paulo Fontes* \\ Doutorando em História Social - UNICAMP
}

RESUMO: A partir da análise da obra Linguagens de Classe do historiador inglês Gareth Stedman Jones e da polêmica por ela provocada (em especial as críticas de Dorothy Thompson), este artigo examina os debates em torno da abordagem proposta pela "guinada linguística" no âmbito da história social.

PALAVRAS-CHAVE: História social, classe, trabalho, "guinada linguística", Gareth Stedman Jones.

ABSTRACT: Based on the analysis of the book Languages of Class, of the English historian Gareth Stedman Jones, and the controversies about it (specially the criticisms of Dorothy Thompson), this article examines the approach of "linguistic turn" on Social History.

KEYWORDS: Social History, Class, Labor, "Linguistic Turn”, Gareth Stedman Jones.

I

Desde meados dos anos oitenta a chamada história social britânica clássica vêm sofrendo sérios questionamentos. Referência fundamental, particularmen-

\footnotetext{
* Autor de Trabalhadores e Cidadãos. Nitro Química: a fábrica e as lutas operárias nos anos 50 (São Paulo: AnnaBlume/Sindicato dos Químicos de São Paulo, 1997).
}

te junto àqueles historiadores preocupados com a história dos trabalhadores e de outros grupos dominados, esta corrente historiográfica consolidou-se através da contribuição de autores hoje internacionalmente conhecidos e influentes como E. P. Thompson, Eric Hobsbawm e Christopher Hill, entre outros. Apesar de sua vasta ampliação temática nos últimos anos, abordando muitas questões para além daquelas rela- 
cionadas exclusivamente à classe operária e sua experiência fabril, a história social parece passar hoje por uma "crise de identidade".

Para muitos dos críticos da história social clássica, esta, em que pese suas tentativas de abordagem temática mais ampla, parece ser incapaz de desvencilhar-se de um pretenso determinismo social enfatizando conceitos como o de identidades coletivas ou experiência de classe, não conseguindo, portanto dar conta de temáticas novas e complexas, como por exemplo a questão de gênero. Joan Scott, uma das historiadoras críticas à "velha" história social resume assim a dificuldade desta em abordar gênero:

"a idéia de que categorias de identidade refletem a experiência objetiva parecia levar a explicações que serviam mais freqüentemente para confirmar do que para contestar as visões dominantes a respeito das mulheres" (SCOTT, 1994).

Os críticos argumentam que a maioria das mudanças políticas e culturais acontecem independentemente dos desenvolvimentos sócio-econômicos, fato que o arcabouço teórico adotado pela história social a impede de incorporar. A maior parte deles propõe, portanto, um aprofundamento do debate teórico sobre a própria disciplina.

Influenciados pelas abordagens intituladas como pós-estruturalistas ou desconstrucionistas (ou ainda pós-modernas para alguns) utilizadas, especialmente, em recentes debates da teoria literária e freqüentemente associadas com obras de Michel Foucault e Jacques Derrida, estes historiadores argumentam a necessidade de se voltar para a linguagem e simbolismos como instituintes de significados e identidades e não apenas como reflexos de determinações

\footnotetext{
${ }^{1} \mathrm{O}$ termo foi retirado do artigo de Miles Taylor, "The Linguistic Turns in British Social History" publicado no Bollettino del diciannovesimo secolo, $\mathrm{n}^{\circ}$ 4, Napoli, 1995.
}

econômicas ou sociais. Daí o termo em inglês linguistic turn, como vêm sendo conhecida este conjunto de críticas e propostas

$\mathrm{Na}$ verdade este é um debate que ultrapassa em muito os limites da história social. No campo da história cultural ou intelectual há algum tempo já se travam sérias e importantes discussões, que envolvem desde a possibilidade da utilização das fontes para se aproximar ao acontecido no passado até as questões da narrativa histórica como ficção ligada a trópicos pré-determinados pela linguagem, colocando em cheque a própria possibilidade do conhecimento histórico. Os debates entre os historiadores Robert Darton (1986) e Roger Chartier (1985) e em torno da obra de Hayden White (1993 e 1994) são alguns exemplos desta polêmica da historiografia atual.

No campo mais tradicional da história social, qual seja, a história do trabalho e dos trabalhadores (labor history, em inglês) este debate iniciou-se e tornou-se cada vez mais acirrado a partir da publicação do livro de ensaios de Gareth Stedman Jones em 1983. Desde então e principalmente na década de noventa, a discussão em torno do linguistic turn e a teoria da história social têm sido, provavelmente, a mais acirrada polêmica no campo da labor history na Inglaterra e nos Estados Unidos.

Cursos, conferências e seminários internacionais têm sido palco de acaloradas discussões entre "novos" e "velhos" historiadores sociais do trabalho. Boa parte deste debate pode ser acompanhada através de revistas especializadas como International Labor and Working Class History e Social History, entre outras, além de alguns livros já organizados em torno desta discussão como o recente Rethinking Labor History: Essays on Discourse and Class Analysis, organizado por Lenard Berlanstein (1993).

Meu objetivo nesse artigo é analisar com mais detalhe os ensaios de Stedman Jones que deram origem a este debate na labor history. Procurarei apresentar e compreender os argumentos de Jones, bem 
como dos críticos ao seu trabalho, em especial a resenha feita por Dorothy Thompson no Bulletin of the Society for the Study of Labor History em 1987.

O debate entre Stedman Jones e Dorothy Thompson e outros é de alguma forma bastante similar à polêmica em torno de gênero e história entre as historiadoras Joan Scott, Louise Tilly e Eleni Varikas (1994). Da mesma forma que Scott, Jones já era um historiador social com uma sólida carreira construída e bastante ligado ao núcleo central da história social clássica, quando no início dos anos oitenta, insatisfeitos com o que consideravam limitações desta, adotam a abordagem linguística para a análise de seus objetos. o que provoca profundas e às vezes indignadas reações em seus antigos colegas.

Nos anos sessenta, Jones, declaradamente marxista, filiou-se ao grupo da New Left Review liderado por Perry Anderson e Tom Nairn, então em grande polêmica com Thompson (1993). Mais tarde, aproximouse da perspectiva teórica de Thompson e lançou um importante livro sobre a cultura popular e o comportamento operário na Londres do final dos século passado (JONES, 1971), completamente vinculado à tradição da "history from below" da labor history britânica. Desde então vem se dedicando ao estudo do declínio da cultura política da classe operária após 1850, provocando um grande abismo cultural e político entre a classe trabalhadora inglesa até a metade do século XIX e os trabalhadores do final daquele século. Stedman Jones chegou a denominar tal diferença de remaking da classe operária inglesa. Tais estudos no final da década de setenta levaram-no à investigação sobre o cartismo e a perspectiva teórica filiada ao linguistic turn.

\section{II}

Linguagens de classe, estudos sobre a história da classe operária inglesa (1832-1982) foi publicado na Inglaterra em 1983. Reunindo cinco ensaios produ- zidos pelo autor no final dos anos setenta e início dos oitenta, o livro abrange uma variada temática, analisando desde a Revolução Industrial até a crise do Partido Trabalhista Inglês na década de setenta deste século, passando pelo debate sobre controle social, cartismo e a cultura operária londrina no final do século XIX.

Na introdução ao livro, Stedman Jones rapidamente trata de explicar os pontos de unidade que ligam todos os artigos. Para ele é o estudo da relação entre sociedade e política na Inglaterra dos séculos XIX e XX e o lugar atribuído à classe operária nestas relações o que une os diversos trabalhos em diferentes períodos e temáticas agora apresentados em uma única obra. Embora muito já tenha sido escrito a respeito, o autor faz questão de frisar que trata-se de questionar as razões que atribuem importância a este tema, baseadas há muito tempo em pressupostos evolucionistas e marxistas.

Para Jones, o conceito de classe joga um papel determinante para a consolidação destes pressupostos. A presença de um forte vocabulário classista constituí um forte traço e uma peculiaridade da história inglesa tornando muito fácil derivar as forças políticas das forças sociais. Esta especificidade inglesa teria tido também fortes consequências teóricas. A teoria de classes marxista, criada a partir da análise do desenvolvimento histórico inglês, aprisionou e transformou em um modelo teórico universal tal especificidade.

Desta forma, através do marxismo, o peso particular da divisão de classes na Inglaterra moldou uma teoria com pretensões universalizantes segundo a qual tal divisão e os conflitos dela decorrentes possuem papel central para a compreensão do desenvolvimento histórico e para a luta social e política. Assim, segundo Jones, reexaminar a história da classe operária inglesa permite iluminar a origem da visão marxista sobre o proletariado e ao mesmo tempo, precisar suas limitações como marco teórico para a interpretação da história.

E seria justamente esta teoria marxista das classes sociais um dos principais alicerces da história 
social britânica surgida a partir dos anos cinqüenta. Desenvolvida a partir dos ricos debates historiográficos no intercâmbio entre a francesa Escola dos Annales e o grupo de historiadores ligados à revista inglesa Past and Present, da crítica às versões economicistas do marxismo fortalecidas após 1956 e do interesse pelos métodos e preocupações da sociologia e da antropologia, esta história social teria para Jones:

"uma ambição totalizadora que desbancaria a estreita visão dos profissionais tradicionais e faria da história o eixo central para a compreensão da política e sociedade modernas” (JONES, 1989, p.5)

Assim os historiadores sociais concentraram seu foco de atenção e uma enorme quantidade de pesquisa na análise dos séculos XIX e XX, buscando reinterpretá-los à luz destas novas abordagens políticas e metodológicas. Enfatizando o antagonismo de classes como ponto central para a análise histórica, historiadores como Eric Hobsbawm, Edward Thompson, Royden Harrison, Perry Anderson, Tom Nairn, entre outros constituíram um conjunto de obras influentes em todo o mundo e que conforma aquilo que poderia chamar-se de história social clássica.

Os ensaios de Linguagens de Classe..., teriam nascido, segundo Jones, de uma insatisfação com as formulações consagradas da história social. Para ele as descrições históricas do social pareciam insuficientes para explicar o político, o ideológico e o cultural. $\mathrm{O}$ determinismo social inerente às concepções teóricas presentes na prática historiográfica dos historiadores sociais seria asfixiante e limitador. Segundo suas próprias palavras:

“(...) me mostrava cada vez mais crítico em relação ao tratamento dominante do 'social' como algo externo e logicamente - e com frequência, ainda que não de maneira inevitável, cronologicamente, anterior a sua articulação por meio da linguagem. O título, Linguagens de Classe, acentua este aspecto: em primeiro lugar, o termo 'classe' é uma palavra incrustada na linguagem e por isso deve ser analisada em seu contexto linguístico; e em se- gundo lugar, dado que há diferentes linguagens de classe, não se deve partir do pressuposto de que 'classe' como elemento básico da descrição social de caráter oficial, 'classe' como efeito do discurso teórico sobre as relações de distribuição ou produção, 'classe' como resumo de um grupo de práticas culturalmente significativas ou 'classe' como espécie de autodefinição política e ideológica compartilhando um único ponto de referência em uma realidade social anterior" (JONES, 1989, p.7).

Stedman Jones assume assim uma mudança de enfoque teórico:

“a 'classe' é tratada como uma realidade mais discursiva que ontológica, centrando o esforço em explicar as linguagens de classe a partir da natureza da política, e não o caráter da política a partir da natureza das classes" (JONES, 1989, p.8).

Como consequência direta deste raciocínio, a explicação para a ação política da classe operária não deveria ser encontrada em sua presumível consciência de classe (ou em sua ideologia) e sim exatamente no oposto, seria a política que geraria a consciência. Da mesma forma, por encarar a linguagem apenas como uma forma pela qual a experiência de classe se expressa, o conceito de experiência é insuficiente e muitas vezes inadequado para a análise histórica da classe trabalhadora.

Enfatizar a linguagem como elemento central da análise histórica significa uma "virada" nos pressupostos e conceitos mais caros à história social (derivados, por sua vez, da determinante influência marxista sobre esta), pois a linguagem desorganiza qualquer idéia de determinação da consciência pelo ser social, porque ela mesma é parte do ser social. Desta forma não podemos:

"decifrar a linguagem política para conseguir uma expressão primeira e material do interesse, já que é a estrutura discursiva da linguagem política que concebe e define o interesse em primeira instância. Assim pois, o que devemos fazer é estudar a produção do interesse, a identificação, a ofensa e a aspiração dentro das próprias linguagens políticas" (JONES, 1989, p.21). 
É o próprio Jones quem nos alerta que um dos últimos ensaios escritos para o livro, "Reconsiderações sobre o cartismo" é o que representa mais fielmente as teorizações expostas acima.

\section{III}

Não por acaso o cartismo foi escolhido por Jones como objeto de sua análise com pretensões de alternativa às abordagens tradicionalmente feitas pela história social. Movimento central na história da classe operária inglesa, o cartismo é tema de um sem número de obras e teses e até hoje objeto de polêmicas e debates historiográficos.

As primeiras aproximações de Stedman Jones com o tema do cartismo deram-se a partir de um projeto paralelo desenvolvido pelo autor. Empenhado na elaboração de uma biografia de Engels, Jones sentiu a necessidade de aprofundar a análise do movimento para ter parâmetros de comparação com a própria descrição do teórico alemão. Ademais, percebia a importância de uma interpretação deste episódio fundamental para ter uma visão global do desenvolvimento da classe operária inglesa.

O que considerava "lacunas" da obra de Edward Thompson, A Formação da Classe Operária Inglesa, também o impulsionou na direção de um estudo mais aprofundado dos cartistas. Jones, a partir da leitura de Thompson, estava preocupado com dois problemas centrais. Em primeiro lugar, por que a consciência de classe descrita por Thompson, alcançou seu ponto culminante com o cartismo e logo depois declinou? Em segundo lugar, qual era exatamente o grupo portador desta consciência, a classe "operária" ou um grupo mais específico de assalariados oficiais e trabalhadores a domicílio enfrentando a proletarização de seus ofícios? ${ }^{2}$

\footnotetext{
${ }^{2}$ Colocada em outros termos, estas constituem questões centrais da historiografia do trabalho britânica. Sua resposta remete à própria periodização sobre a formação da classe operária inglesa.
}

Diante destas questões, Stedman Jones colocou como objetivo central a compreensão do caráter político do cartismo e as razões de seu ascenso e sua queda. Desta maneira, inicia seu artigo questionando o consenso existente entre os analistas em caracterizar o cartismo primordialmente como um fenômeno social, desconsiderando-o enquanto um movimento político. Tal consenso teria sua origem entre os próprios observadores contemporâneos. De um lado, a vertente de análise inaugurada por Engels em A Situação da Classe Trabalhadora na Inglaterra, que via o cartismo como a expressão política do novo proletariado industrial, sendo assim uma espécie de confirmação empírica da concepção marxista de consciência de classe. Por outro lado, outra variante analítica bastante influente com origem liberal identificava o cartismo como expressão dos tecelões e outros grupos "pré-industriais" decadentes. Em qualquer uma destas diferentes versões e de seus desdobramentos, entretanto, a composição social e o caráter de classe do cartismo apareceria como um ponto central da análise.

Stedman Jones, portanto, propõe reconsiderar esta visão tradicional a partir de uma análise minuciosa da própria linguagem dos cartistas. Ao fazê-lo, não tenciona o estudo de uma determinada consciência de classe ou profissional que seria expressa a partir do cartismo. Para ele a linguagem cartista não é a tradução de uma experiência em palavras, e deve, conseqüentemente ser analisada em si mesma e não a partir de um a priori social. Procedendo-se desta maneira têm-se a dupla vantagem de partir do que escreveram e disseram os cartistas e de perceber as relações entre a interpretação social e a interpretação linguística.

Ver por exemplo a posição de Eric Hobsbawm, polemizando elegantemente com algumas conclusões de Thompson, em seu artigo "O fazer-se da classe operária inglesa, 1870-1940”. In: Mundos do Trabalho - Novos Estudos sobre História Operária. Rio de Janeiro: Paz e Terra, 1987. 
Assim, esta análise linguística mostra que o cartismo foi fundamentalmente um movimento político. Articulou uma solução política para a miséria e os problemas cotidianos daquelas pessoas através de uma linguagem, de um vocabulário político que transmitia esperança e propostas possíveis de serem compartilhadas por aqueles que a ela aderiam. Somente tal abordagem permite responder à questão decorrente do enfoque social, mas não explicada por ele, qual seja, por que os descontentamentos econômicos e sociais assumiram a forma cartista? Ou colocado de outra forma, por que uma ação tida como contra a miséria e a dominação econômica encontrou sua expressão em um movimento que tinha como eixo central a defesa do sufrágio universal? Ao subestimar em suas análises o programa político dos cartistas situando-o como mera expressão de um descontentamento social, os historiadores sociais não tem conseguido responder e enfrentar tais questões.

Para começar a respondê-las, ressalta Jones, é preciso desde logo criticar a idéia determinista do poder econômico como causa e do poder político como efeito. Prontamente, o autor nos lembra que nem todos os historiadores sociais compartilham de tal simplificação. Edward Thompson, por exemplo, já havia demonstrado, em A Formação da Classe Operária Inglesa como a experiência dos trabalhadores em finais do século XVIII e princípios do XIX estava ligada tanto à exploração econômica quanto à repressão política desencadeada pelo Estado britânico.

Entretanto, prossegue Jones, é preciso ir mais longe do que Thompson:

"A simples dialética entre consciência e experiência não pode explicar a forma precisa que assumiu a ideologia cartista.(...) Não era uma simples experiência, mas também uma determinada ordenação linguística da experiência, o que podia levar as massas a crer que 'sua exclusão do poder político é a causa de nossas anomalias sociais' e que o 'poder político' era a causa da 'opulência'. A consciência não pode se relacionar com a experiência a não ser que se interponha entre ambas uma determinada linguagem que organiza a compreensão da experiência e é importante sublinhar que um mesmo conjunto de experiências pode ser articulado por mais de uma linguagem" (JONES, 1989, p.97).

Desta forma é possível perceber que:

"A linguagem de classe não era simplesmente uma verbalização da percepção ou o afloramento à consciência de um fato existencial, como tem suposto as tradições sociológicas e marxista. Mas tampouco era simplesmente a articulação da experiência acumulativa de uma forma determinada de relações de classe. Estruturava-se e inscrevia-se dentro de uma complexa retórica de associações metafóricas, deduções causais e construções imaginativas" (JONES, 1989, p.97).

Para Stedman Jones tal linguagem encontrava suas bases e provinha do radicalismo. Estruturado coerentemente nos anos 1770, o radicalismo tornouse, a partir da década de 1790, um instrumento das aspirações políticas plebeias. Tendo como pressupostos uma crítica radical ao monopólio e concentração do poder político e seus consequientes efeitos corruptores sobre a sociedade inglesa (a "Velha Corrupção" nos termos de Cobbett) e a defesa do sufrágio universal masculino, o radicalismo teria se convertido na linguagem de classe do movimento cartista.

Para tanto, porém, foi necessário que, no início do século XIX ele ampliasse seu vocabulário político incorporando temas e termos que dessem conta da miséria e do descontentamento dos setores populares atribuindo, assim, uma origem política às calamidades econômicas que atingiram a população mais pobre. Se, de um lado tal ampliação significou um distanciamento da classe média e uma clara identificação com a classe operária, por outro lado, isto não resultou em uma reestruturação das premissas básicas da ideologia. Sua identidade não era com algum grupo específico e sim com o "povo" e com a "nação", além disso, o dogma central do radicalismo, qual seja. atribuir a miséria, o desemprego, os baixos salários e outras dificuldades materiais às causas políticas permaneceu inalterado. 
Desta maneira, o radicalismo tornar-se-ia a ideologia dominante do movimento popular, sendo assim a linguagem de classe do movimento cartista. A decadência e a crise do cartismo deve ser entendida como a incapacidade do radicalismo no final dos anos quarenta em dar respostas às reivindicações e desejos populares. Jones procura mostrar então, como se deu o diálogo entre o radicalismo e outras concepções políticas e sociais também presentes e atuantes naquele período e como estas concepções ao mesmo tempo que influenciaram o radicalismo, particularmente a partir de 1832, foram também profundamente influenciadas por este.

O sindicalismo desenvolvido a partir de 1815 , por exemplo, crescentemente confrontava-se com um empresariado industrial hostil, apoiado na ideologia da economia política e cada vez mais orientado para o mercado externo, e por isso mesmo cada vez menos respeitoso em relação às tradições e costumes da classe operária. Aparentemente tal sindicalismo entraria em choque com algumas das premissas do radicalismo original, desenvolvido por Paine e Cobbett, segundo as quais a harmonia reinaria nas relações entre patrões e operários não fosse pelo parasitismo do Estado e seus asseclas.

Entretanto, inclusive pelo fato da maioria dos sindicalistas serem abertamente radicais, e pela mútua influência entre radicalismo e sindicalismo, a economia política não era vista como ideologia de uma classe e sim como uma visão de mundo não humana e egoísta. Conseqüentemente também os patrões não eram vistos enquanto uma classe antagônica, a não ser os "mau patrões". Os capitalistas eram associados mais ao sistema político que ao poder econômico, mostrando assim a influência determinante do radicalismo no seio das idéias sindicais.

Stedman Jones também analisa detidamente outras concepções como o owenismo e o socialismo ricardiano, procurando mostrar como a linguagem radical atribuindo um peso decisivo à política permaneceu predominante entre os trabalhadores ingleses das décadas de 1830 e 1840 , mesmo quando influenciada por estas novas concepções.

Assim, o radicalismo do período cartista não via o conflito entre empregadores e empregados como fundamental. Este dar-se-ia entre os trabalhadores e as "classes ociosas" que controlavam e sugavam o Estado. Os patrões ocupariam um lugar intermediário entre o "trabalhador produtor e o consumidor ocioso" (JONES, 1989, p.138). Era um aliado dos opressores, mas não controlaria o sistema. Era duramente criticado, não por sua posição econômica, mas por suas crenças políticas e atitudes sociais.

Mesmo no final da década de 1830 no norte do país onde os conflitos trabalhistas se acirraram bastante e os industriais passaram a ser identificados como principais inimigos, os pressupostos radicais ainda teriam permanecido presentes, já que reforçou a idéia de que fora a expropriação da terra imposta por meios políticos a principal responsável pela situação dos trabalhadores e pela tirania patronal.

Jones argumenta que é possível explicar a forma cartista adotada pelo descontentamento popular a partir da segunda metade dos anos trinta percebendo que radicalismo, que era a linguagem básica dos cartistas, partia. como foi visto do papel opressivo do poder monopolista e do Estado. Assim, as ações intervencionistas governamentais ao longo daquela década buscando impor definitivamente as idéias da economia política por sobre os trabalhadores, reforçavam e justificavam plenamente aquela concepção. Da mesma forma, teriam contribuído para a definição da forma cartista, o fracasso das alternativas sindicalistas e owenistas desencadeadas ao longo do período anterior. Assim a força da Carta no final da década de trinta advinha da identificação que o radicalismo propunha do poder político enquanto fonte de opressão social e de sua capacidade de propor o sufrágio como forma de desmantelamento deste poder através da possibilidade de representação conferida aos trabalhadores. 
Sua debilidade estava, entretanto, em sua incapacidade de articular alianças em outros setores sociais. Havia uma grande contradição em aplicar uma estratégia radical em um movimento de composição exclusivamente operária. Tal contradição paulatinamente colocou em cheque as próprias premissas da estratégia radical e desta forma:

"como sistema de crenças que era, o cartismo começou a debilitar-se quando se abriu um abismo entre suas premissas e as idéias de seus apoiadores" (JONES, 1989, p.102).

O Estado, ao conceder o direito de voto às classe médias em 1832 e ao desencadear políticas de eliminação de algumas fontes materiais de descontentamento popular, atingiu profundamente qualquer estratégia radical e selou o fim do movimento cartista. Segundo Stedman Jones devemos, portanto, analisar a decadência e crise do cartismo não como resultado da prosperidade econômica:

"Um exame atento da linguagem do cartismo sugere que sua ascensão e queda devem ser relacionadas em primeira instância, não com as mudanças da economia, as divisões do movimento ou uma consciência de classe imatura, e sim o caráter e a política do Estado, o inimigo principal de cujas ações os radicais sempre haviam pensado que dependia sua credibilidade" (JONES, 1989, p.174).

Finalmente, Jones retorna à questão do caráter social do cartismo. Para ele parece claro compreender que o cartismo não foi um movimento que expresse uma pretensa consciência da classe operária. O cartismo foi um movimento operário, menos por seu desejo e mais pela incapacidade do radicalismo em atrair os setores médios para suas idéias. Assim, o cartismo deve ser visto como uma forma de radicalismo e não simplesmente como um movimento de classe.

"O cartismo foi a última versão, mais importante e mais desesperada, ainda que provavelmente a mais revolucionária, da crítica radical da sociedade, que havia desfrutado uma existência quase ininterrupta desde as décadas de 1760 e 1770 . A visão desta crítica era a de uma sociedade mais ou menos igualitária, composta exclusivamente pelas classes produtoras e com o mínimo de necessidade de um governo. O poder político, tal como os cartistas o entendiam, em sintonia com os radicais do século XVIII, era fundamentalmente um fenômeno negativo (...) A divisão [na sociedade] não se estabelecia primordialmente entre classes dominantes e classes exploradas no terreno econômico, e sim entre beneficiários e vítimas da corrupção e do monopólio do poder político" (JONES, 1989, p.165).

\section{IV}

O ensaio de Stedman Jones, evidentemente, provocou inúmeras reações. Enfatizando o papel da linguagem política em detrimento da consagrada interpretação social do cartismo, Jones claramente visava introduzir uma inovadora perspectiva teórica nas abordagens historiográficas sobre a classe operária. Além disso, ao questionar o caráter de classe do movimento cartista (essencial para as análises marxistas) e as próprias noções de consciência ou experiência da classe (redefinidas na historiografia pela obra de Thompson), Stedman Jones desferia um ataque a alguns dos mais importantes pressupostos da história social desde os anos sessenta.

Naturalmente uma grande quantidade de artigos e resenhas críticas tomou conta dos jornais e revistas especializadas na Grã-Bretanha e Estados Unidos. Brian Palmer em seu livro Descent into Discourse cita cerca de doze respostas à obra de Jones publicadas entre 1984 e 89 (PALMER, 1990) ${ }^{3}$.

\footnotetext{
${ }^{3}$ Os textos citados por Palmer são: John Foster, “The declassing of Language", New Left Review 150 (1985); Paul Pickering, "Class without Words: Symbolic Communication in the Chartist Moviment", Past and Present 112 (1986); Joan Scott, "On Language, Gender and Working-Class History", International Labor and Working-Class History 31 (1987); Dorothy Thompson, "The Languages of Class" in Bulletin of the Society for the Study of Labor History 52, $\mathrm{n}^{\circ} 1$ (1987); Neville Kirk, "In Defence of class: A critique of recent revisionist writing on the nineteenth-century
} 
No âmbito desse artigo concentraremos nossa atenção na crítica feita por Dorothy Thompson. Um dos nomes mais famosos da história social britânica, Thompson especializou-se no estudo do movimento cartista. Seus livros The Chartists e The Chartist Experience (este co-organizado com J. Epstein) constituem verdadeiros clássicos da história social sobre o tema. Sua resenha a Linguagens de Classe... nos dá uma excelente dimensão do debate aberto pela obra de Stedman Jones já que sintetiza grande parte das críticas e considerações feitas pelos historiadores sociais "tradicionais".

O primeiro questionamento de Dorothy Thompson diz respeito à própria concepção de linguagem que transparece do texto de Jones. Sua visão da linguagem dos cartistas seria altamente restritiva já que analisa apenas os conceitos políticos expressos a partir dos artigos de jornal dos cartistas, ignorando outras formas de comunicação e expressão verbais e não-verbais. Para um autor tão preocupado com o papel decisivo da linguagem tal "esquecimento" é altamente comprometedor.

James Epstein também toca nesta ferida lembrando que ao concentrar-se excessivamente na linguagem política formal, Jones não abordou a variada e rica cultura oral e visual do período. Como lembra Brian Palmer, Stedman Jones foca seu estudo exclusivamente na linguagem pública, tal como ela foi noticiada por parte da imprensa cartista. Ao fazê-lo operou uma

English work class", International Review of Social History 32 (1987); Robert Gray, "The desconstructing of the working English class", Social History 11 (1986); James Epstein, "Rethinking the categories of Working Class History", Labor/Le Travail 18 (1986) e "Understanding the Cap of Liberty: Symbolic Practice and Social Conflict in early Nineteenth-Century England", Past and Present 122 (1989); Nicholas Rogers,"Chartism and Class Struggle", Labor/Le Travail 19 (1987); Christopher Clark, "Politics, Language and Class", Radical History Review 34 (1986). redução da linguagem ao vocabulário publicado pelo radicalismo.

Assim, longe de estar revolucionando o estudo da história dos trabalhadores através da linguagem, Jones nada mais estaria fazendo do que a velha história das idéias políticas.

"O que está em discussão neste ensaio sobre o cartismo não é nada mais do que a antiga - e aqui lamentavelmente de velho estilo - disciplina do Pensamento Político" (THOMPSON, 1987, p. 56).

Uma outra grave conseqüência deste procedimento adotado por Jones vai de encontro a um dos preceitos básicos da história social do trabalho desde os anos cinqüenta, qual seja, o de não identificar a história dos movimentos operários com a história das ideologias destes movimentos e de não reduzir a história da classe à história do movimento ou de suas organizações ${ }^{4}$. Stedman Jones analisa a linguagem de certas lideranças da classe e generaliza afirmando abordar a linguagem de classe como um todo. Desta forma os cartistas (ou uma parte deles como asseguram Palmer e Thompson) substituem a classe com um todo na perspectiva do autor.

Tais problemas também estão diretamente ligados à seleção e utilização das fontes feita por Jones. Como destaca Palmer, suas evidencias são altamente seletivas e questionáveis. Quase toda sua argumentação é feita a partir da análise de dois jornais cartistas, o Northern Star e o Poor Man's Guardian. A utilização destes jornais não leva em conta suficientemente as disputas e diferenças no interior do cartismo privilegiando sua vertente mais próxima do discurso radical do século XVIII. A linguagem de dois jornais

\footnotetext{
${ }^{4}$ A este respeito ver o clássico ensaio de Eric Hobsbawm, História Operária e Ideologia. In: Mundos do Trabalho - Novos Estudos sobre História Operária. Rio de Janeiro: Paz e Terra, 1987.
} 
não pode ser identificada como a linguagem de todo movimento cartista. Além disso, os jornais cartistas atuavam nas margens da legalidade e submetidos portanto a uma série de restrições em sua linguagem. Não é possível para um historiador desconhecer o contexto de produção de suas fontes. Dorothy Thompson destaca que a linguagem dos cartistas deve ser também procurada em inúmeras outras fontes disponíveis como:

"Relatos de espiões, documentos de julgamentos, cartas de magistrados e outras fontes que freqüentemente revelam uma mais nítida e agressiva retórica” (THOMPSON, 1987, p.56).

Para Thompson um dos grandes problemas do texto de Stedman Jones é a separação dicotômica e radical que ele faz entre o cartismo como movimento político e do cartismo como fenômeno social. Como conseqüência ele desconsidera o cartismo como um movimento da classe operária, embora feito por esta.

Dorothy Thompson procura mostrar as lacunas da contextualização feita no ensaio. Lembra que, ao contrário do que afirma Jones, muitos observadores contemporâneos como Disraeli já chamavam atenção para o caráter político do cartismo. Isto porém não significava e não significa descaracteriza-lo enquanto movimento social.

Stedman Jones ao selecionar os jornais como fontes praticamente únicas e desprezar uma série de outras perde de vista a enorme diferença entre os contextos do radicalismo no final do século XVIII e em meados do XIX, embora muito do que era escrito fosse semelhante e até idêntico em alguns casos. Utiliza uma caracterização muito linear e mecânica do radicalismo, desprezando a possibilidade de reelaboração de tradições pela ação humana. A história da classe operária está recheada de eventos nos quais demandas sociais participam lado a lado e misturamse com lutas por direitos políticos, quebrando qualquer separação mecânica entre estas duas esferas.

Jones considera a crise e o fracasso do cartismo quase que como pré-determinados na medida em que a linguagem radical isolou-se no seio da classe operária e não conseguiu alianças nos setores médios. Além disto, a mudança da postura do Estado, iniciando uma série de reformas sociais teria tornado inoperante a lógica da argumentação cartista.

Tal argumentação, além de em grande medida teleológica pois quase que determina a priori a derrota cartista, perde de vista ou despreza a existência de lutas e conflitos na sociedade. Jones subestima a ameaça permanente da mobilização cartista e o temor que ela provocava nos setores dominantes da sociedade. As reformas empreendidas pelo Estado aparecem assim unicamente como decisões espontâneas do Estado e das classes dirigentes e não também como frutos das pressões cartistas.

O texto de Stedman Jones, mesmo negando o tempo todo tal intenção, é em grande medida determinista. A linguagem política radical praticamente determina o curso de todo o movimento cartista. Ele não se preocupa em explicar e contextualizar o surgimento e as origens da linguagem radical, com exceção de vagas e pontuais referências aos setores médios e ao "radicalismo original de Paine e Cobbett". A linguagem parece o tempo todo acima dos sujeitos e de suas aspirações e ações, praticamente conduzindo-os como marionetes no "cenário histórico".

Como muito apropiadamente Dorothy Thompson chama à atenção, Stedman Jones disfarçadamente cobra da classe operária uma outra consciência que não fosse o radicalismo da classe média. Há uma certa, "leninista, talvez platônica", idéia de "falsa consciência" permeando a argumentação de Jones. Com refinado humor britânico, Thompson relembra a Jones uma das lições básicas do ofício do historiador levada muito a sério por profissionais vinculados desde a escola dos Annalles até a tão criticada historiografia social inglesa:

"Tais historiadores [como Stedman Jones], com as vantagens da posteridade e do acesso a informações não disponíveis aos 
contemporâneos, podem dizer qual o programa apropriado que cada classe deveria ter e como devem se aproximar da sua verdadeira consciência" (THOMPSON, 1987, p.56).

Não por acaso Eleni Varikas, debatendo com a abordagem linguística de Joan Scott, nos recorda, citando Raymond Willians, o quanto tal abordagem pode ser determinista, vinculando-se historicamente a premissas de determinação bastante similares às do marxismo ortodoxo (VARIKAS, 1994)

\section{BIBLIOGRAFIA}

BERLANSTEIN, Lenard. Rethinking Labor History: Essays on Discourse and Class Analysis. Chicago: University of Illinois Press, 1993.

CHARTIER, Roger. "Text, symbols and Frenchness". In: The Journal of Modern History 57, n. ${ }^{\circ}$ 4, 1985.

DARTON, Robert. "Os trabalhadores se revoltam: o grande massacre de gatos na Rua Saint-Severin”. In: O Grande Massacre de Gatos, Rio de Janeiro: Graal, 1986.

GINZBURG, Carlo. A Micro-História e outros ensaios, Rio de Janeiro: Difel, 1989.

JONES, Stedman Gareth. Outcast London: a study in the relationship betwin classes in Victorian society, Oxford, 1971. . Lenguages de clase. Estudios sobre la historia de la clase obrera inglesa (1832-1982). Madid: Siglo Vinte e Uno, 1989.

HOBSBAWM, Eric. Mundos do Trabalho - Novos Estudos sobre História Operária. Rio de Janeiro: Paz e Terra, 1987.

PALMER, Brian. Descent into Discouse. The Reification of Language and the Writing of Social History. Philadelphia:
Assim, ao contrário de um procedimento teórico novo e revelador, Jones nos ofereceria pouco mais do que uma velha história das idéias políticas, recheadas de a prioris e determinações linguísticas. Irônica, Dorothy Thompson adverte e finaliza afirmando que este é o risco de quem "traz demasiadas pré-concepções teóricas ao estudo das evidências históricas" (THOMPSON, 1987, p.57).

Temple University Press, 1990.

SCOTT, Joan. "Prefácio a Gender and Politics of History". In: Cadernos Pagu, no 3, Campinas: IFCH, Unicamp, 1994.

TAYLOR, Miles. "The Linguistic Turns in British Social History". In: Bollettino del diciannovesimo secolo, $\mathrm{n}^{\circ}$ 4, Napoli, 1995. THOMPSON, Dorothy. "The Languages of Class". In: Bulletin of the Society for the Study of Labor History $52, \mathrm{n}^{\circ} 1,1987$.

THOMPSON, Edward Palmer. A Peculiaridade dos Ingleses. Campinas: IFCH-Unicamp, 1993.

TILLY, Louise A. "Gênero, história das mulheres e prática social". In: Cadernos Pagu, no 3 .

VARIKAS, Eleni. "Gênero, experiência e subjetividade: a próposito do desacordo Tilly-Scott". In: Cadernos Pagu, no 3, Campinas: IFCH-Unicamp, 1994.

WHITE, Hayden. Trópicos do Discurso: Ensaios sobre a crítica da Cultura. São Paulo: Edusp, 1994.

Meta-História: a imaginação histórica no século XIX na Europa, São Paulo: Edusp, 1993. 